119.2:M66/4/DATE

INTERIOR DEPARTMENT

GEOLOGICAL SURVEY

USE AND CONSERVATION OF MINERALS 
I $19.2: M 66 / 4 / 176$

\section{Use and Conservation of Minerals}
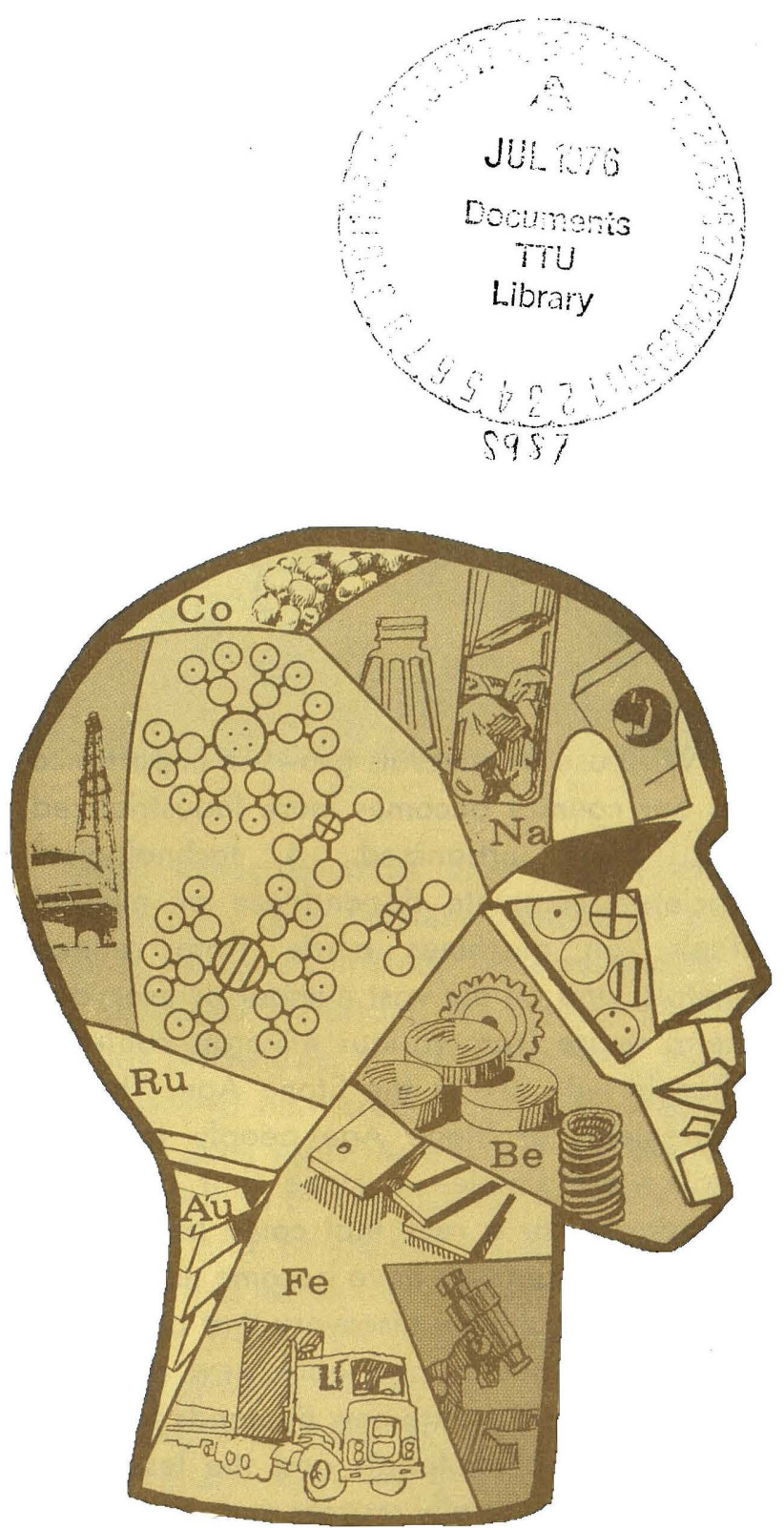


\section{USE and CONSERVATION}

\section{of MINERALS}

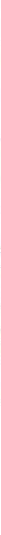

Wise use of minerals grows in importance as our country becomes more industrialized and more urbanized. A technological society's complete dependence on mineral fuels, on machines made from refined metals, and on the vast number of everyday items made from various minerals contrasts sharply with life in the Stone Age. The requirements of Stone Age people for minerals were simple-a stone that could be sharpened, or a rock that could be thrown. Man's requirements have become more complex with each new discovery that answered recognized needs, and each new research effort seems to create new demands for both the traditional materials and the less wellknown and generally scarcer materials.

At the end of World War I, only 50 of the 92 naturally occurring elements were used, and only 20 of these in significant 
amounts. At present, scientists are finding potential use for nearly all the elements. About 70 of them are commercially available and about 34 are used in sizable quantities. In addition to elemental materials, about 50 major kinds of rocks and minerals are used and marketed. Mineral resources are extremely important to our national economy.

Raw materials produced each year by the domestic mineral industry amount to about 4 percent of the Gross National Product (GNP), and the manufacturing of mineral products accounts for another 10 to 15 percent of the GNP. When the total value of all goods and services is traced to its ultimate source, nearly every dollar of the GNP is dependent on a man operating a machine that was made from a mineral product and is powered by a mineral fuel.

The large demand for mineral products requires an equal or greater quantity of

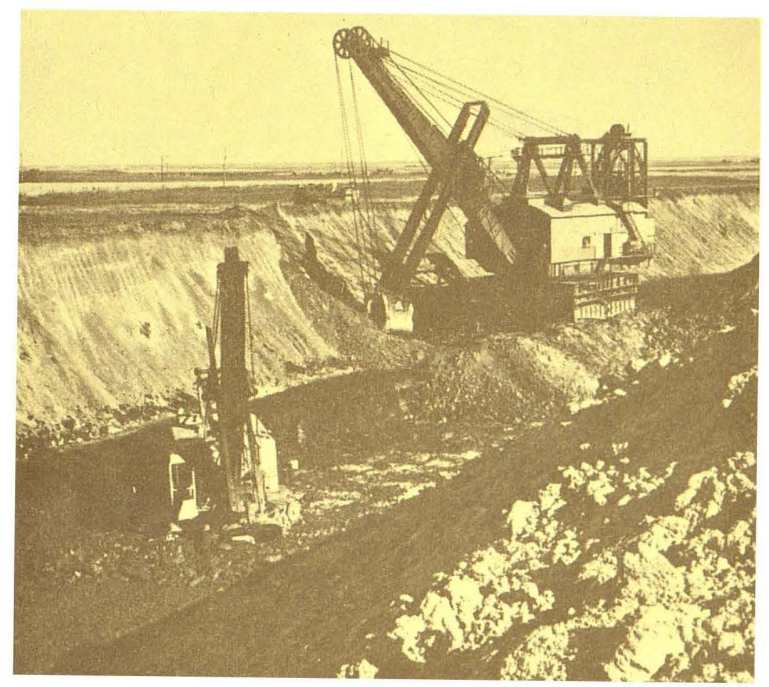

Strip mining lignite at the Velva mine near Velva, North Dakota. The large 22-yard shovel is removing overburden; the smaller shovel is mining lignite. 


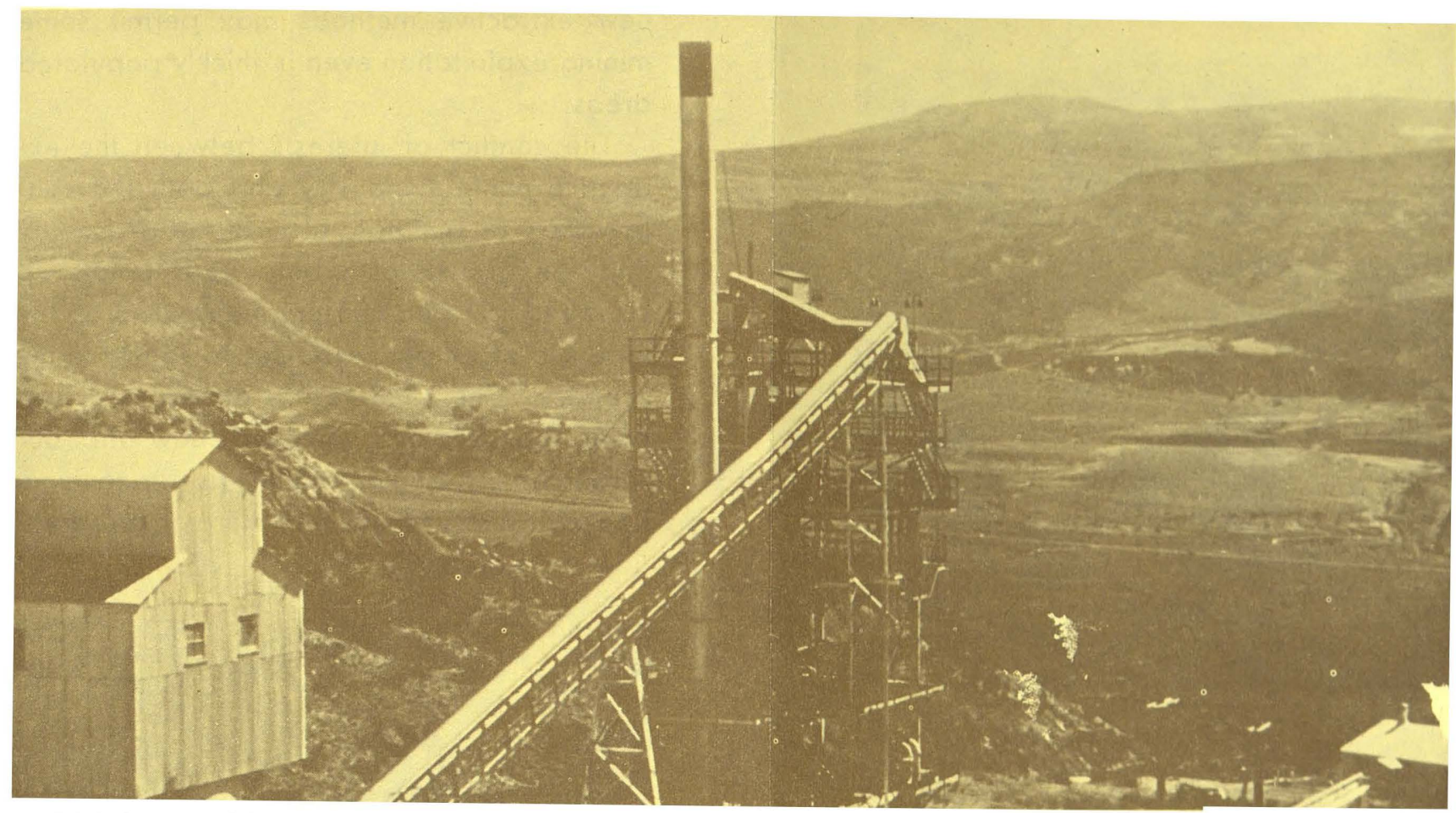

Oil shale retort of the Anvil Points Experiment Station, Naval Oil Shale Reserve, Garfield, Colorado, is extracting oil by heating the shale.

mineral raw materials, and each demand presents supply problems. For some few mineral commodities, the supply is nearly inexhaustible; it is only necessary to select the source nearest to the point of use. For the great majority, the supplies are relatively limited, and new sources are the object of continuous search by geologists and the mining industry.

Natural concentrations of many minerals are widely but sparsely distributed in nature. Locating these national resources is a major task of the U.S. Geological Survey, and many Survey publications describe in detail the mineral resources of specific areas and summarize information about individual mineral commodities.
Many conservationists limit their efforts to finding the least wasteful method of extracting all of a particular mineral deposit. This is indeed important, for mineral assets are not renewable in the sense that food crops are-a new crop of minerals cannot be grown each year. The efficient and practical exploitation of our mineral wealth is encouraged and controlled by a variety of economic and legislative measures.

Another aspect of conservation that has received growing emphasis is the desire of many people to enjoy our natural heritage without interference from man's activities. Extractive mining has not always been accomplished in ways that preserve natural beauty. Competition between the need for 


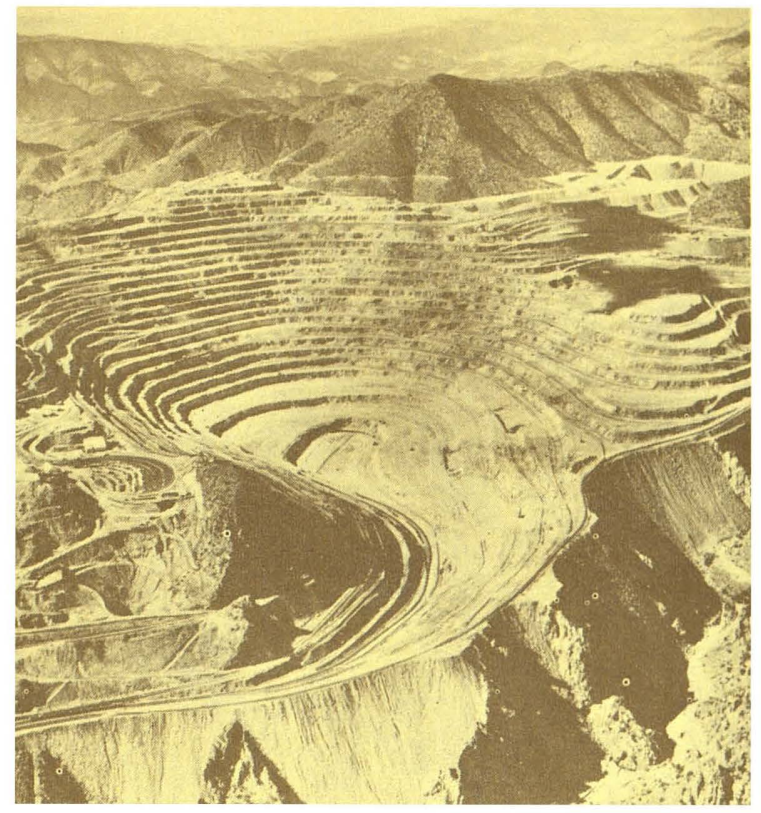

Morenci open pit copper mines, Greenlee County, Arizona.

minerals and the demand for beauty is resulting in improved mining practices, restoration of mined-out areas, and improved conservation. Because of our very real need for mineral raw materials and the best possible environment for our growing population, maximum attention to both of these requirements is necessary.

The conflict between the need for urban areas and the need for minerals is a slightly different but closely related aspect of conservation. The expanding population is creating a larger demand for minerals and at the same time is spreading over a much greater area, which thus becomes unavailable for conventional extractive mining. Ideally, minerals should be extracted before urbanization extends to particular areas having exploitable resources. Where such logical development has not been possible, 
new extractive methods may permit some mining exploitation even in thickly populated areas.

The conflict of interests between the extractive mineral industry and both the conservation of our natural heritage of beauty and the growth of urban areas points up the need for true conservation, which is the wise use of all our resources to satisfy many purposes. The multiple use of resources becomes possible only when we know what our resources are and plan their use in conjunction with plans for development or preservation of an area.

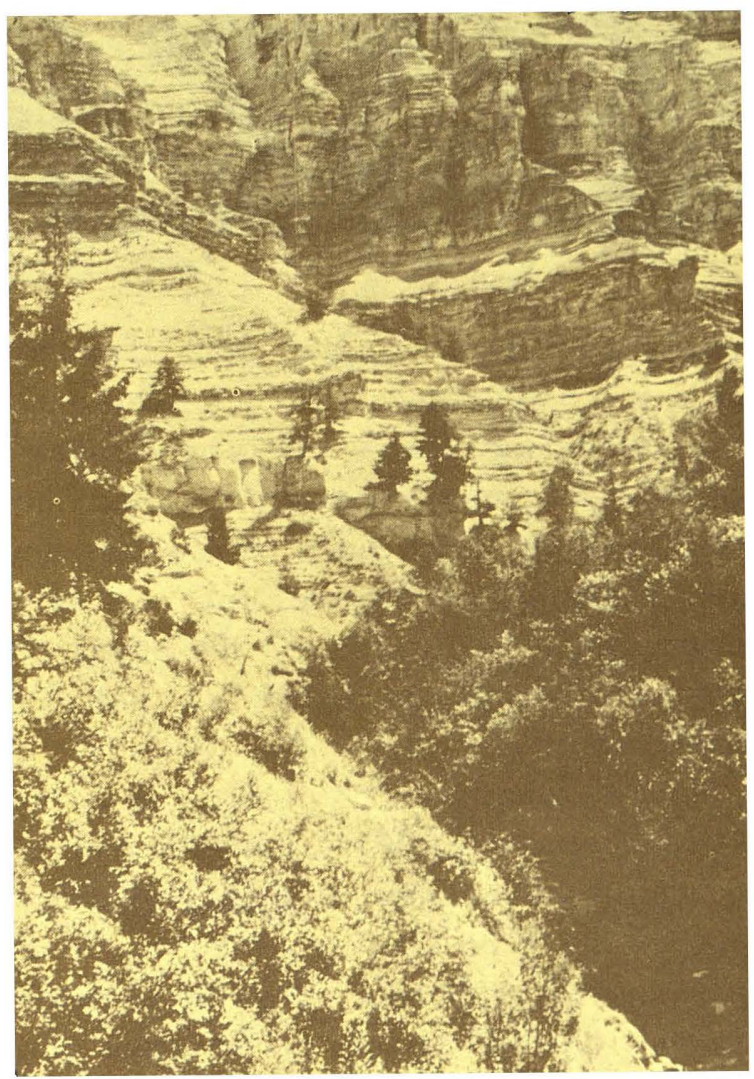

A closeup of the rich oil shale exposed in a quarry in the Piceance Basin near DeBeque, Colorado. 
As the Nation's principal conservation agency, the Department of the Interior has responsibility for most of our nationally owned public lands and natural resources. This includes fostering the wisest use of our land and water resources, protecting our fish and wildlife, preserving the environmental and cultural values of our national parks and historical places, and providing for the enjoyment of life through outdoor recreation. The Department assesses our energy and mineral resources and works to assure that their development is in the best interests of all our people. The Department also has a major responsibility for American Indian reservation communities and for people who live in Island Territories under U.S. administration.

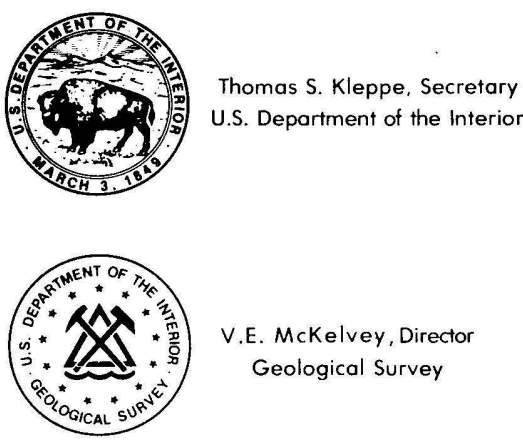


